Linguagem em (Dis)curso, Palhoça, SC, v. 9, n. 3, p. 549-564, set./dez. 2009

\title{
TEXTOS E HIPERTEXTOS: PROCURANDO O EQUILÍBRIO*
}

\author{
Carla Viana Coscarelli**
}

\begin{abstract}
Resumo: Neste texto discuto a questão "até que ponto precisamos tratar o hipertexto de forma diferente do texto no que diz respeito aos fatores de textualidade". Defendo que todo texto é um hipertexto e que toda leitura é um processo hipertextual. Acredito que se o texto estiver bem escrito, ou seja, estiver adequado ao leitor, e o leitor for bom, a leitura irá gerar resultados satisfatórios. Textos mal escritos e leitores pouco hábeis vão gerar um resultado muito ruim independente do formato de apresentação do texto (impresso ou hipertextual). Precisamos, portanto, ensinar nossos alunos a lidar com textos variados, de gêneros diversificados, em todos os ambientes, inclusive o digital. Apresento um levantamento dos elementos dos ambientes digitais que aparecem em livros didáticos de Língua Portuguesa, a fim de verificar como esses materiais contribuem para o letramento digital dos alunos.
\end{abstract}

Palavras-chave: hipertexto; textualidade; livro didático.

\section{INTRODUÇÃO: O QUE HÁ DE NOVO?}

Quando se trata de leitura e escrita, textualidade e textualização ${ }^{1}$, precisamos mesmo pesquisar o hipertexto como alguma coisa diferente do texto?

\footnotetext{
* O texto original foi apresentado em uma mesa redonda intitulada Hipertexto: referenciação, leitura e escrita, no II Encontro Nacional sobre Hipertexto, realizado de 25 a 27 de outubro de 2007.

** Professora da Faculdade de Letras da Universidade Federal de Minas Gerais, Belo Horizonte, MG, Brasil. Doutora em Linguística. Email: <cvcosc@yahoo.com.br>.

1 "podemos definir melhor textualidade como um princípio geral que faz parte do conhecimento textual dos falantes e que os leva a aplicar a todas as produções linguísticas que falam, escrevem, ouvem ou lêem um conjunto de fatores capazes de textualizar essas produções" (COSTA VAL, 2004, p. 115). A textualização, por sua vez, é a interpretação que cada leitor ou ouvinte faz do texto. Cada texto pode ser textualizado de maneiras diferentes por diferentes pessoas e em diferentes situações.
} 
$\mathrm{Na}$ minha pesquisa de doutorado (COSCARELLI, 1999), estudei a influência da imagem na produção de inferências, e, consequentemente, na compreensão de textos informativos. Comparei a leitura de textos com imagens (vídeos curtos) e sem imagens em um ambiente de navegação restrita.

Esta pesquisa me permitiu concluir que a imagem que ilustra e complementa o texto verbal contribui positivamente para a compreensão deste, uma vez que leva o leitor a gerar mais inferências conectivas, que são imprescindíveis à compreensão. No entanto, para a otimização da combinação desses dois estímulos (texto e imagem), é preciso que texto e imagem ofereçam ao leitor informações complementares (e não, redundantes). Ou seja, para funcionar bem, gerando melhores resultados na compreensão do texto, imagem e texto devem se complementar e não se sobrepor. Isso significa que há uma forma de fazer esse texto que gera melhores resultados de leitura.

A pesquisa realizada por Dias (2008) verifica se há diferença entre a leitura de um hipertexto cujos links partem de uma imagem e a leitura de um hipertexto cujos links partem de um texto verbal. Essa pesquisa nos ajuda a compreender como os leitores percebem diferentes organizações de um hipertexto, e como se comportam quando precisam lidar com elas. Para verificar a influência do formato de organização do hipertexto na compreensão, Dias (2008) verificou a diferença de comportamento de grupos de leitores em três versões de um mesmo texto - uma com os links partindo de uma imagem, outra cujos links eram elementos verbais e uma terceira versão que integrava imagem e elementos verbais. Com esse experimento, o autor pôde concluir que, apesar de a versão verbal gerar um melhor desempenho inicialmente, muito provavelmente devido à sua semelhança com a organização dos textos impressos com os quais os leitores já estão familiarizados, "Os leitores da versão integrada desenvolvem uma melhor compreensão do hipertexto após um período de navegação contínua. [...] a organização exclusivamente imagética, parece desorientar o leitor, levando-o a desistir da navegação" (p. 131). Esses resultados nos levam a crer que é preciso estar atento para o design dos textos tanto no que diz respeito ao seu layout, quanto à organização do seu conteúdo e à sua forma de expressão. Um texto com problemas de escrita, organização e/ou formatação irá dificultar o trabalho do leitor. 
Uma pesquisa que realizamos mais recentemente sobre a leitura de hipertextos (COSCARELLI, 2005b, 2007) nos permitiu dizer que a leitura da versão hipertextual (texto digital subdividido em pequenas partes com links e menu para navegação) não gera melhores resultados que a leitura do mesmo texto em formato contínuo (texto "corrido" em que todas as partes são apresentadas em parágrafos consecutivos). Apenas no caso da localização de informação explícita há uma pequena vantagem para o formato de apresentação hipertextual. Ou seja, essa pesquisa nos mostrou que, quando os sujeitos são leitores maduros e familiarizados com a tecnologia, a leitura em formato hipertextual não gera uma compreensão do texto qualitativamente diferente daquela que resulta da leitura do mesmo texto em formato contínuo.

Outros experimentos como os descritos em Rouet et al. (1996) apontam também para essa pouca discrepância entre resultados encontrados nos dois formatos de apresentação de textos. Acredito que isso se justifique pelo fato de que todo texto seja um hipertexto e que toda leitura seja um processo hipertextual. Esses experimentos indicam que o texto estando bem escrito, ou seja, respeitando regras de textualidade do seu gênero e estando adequado ao leitor, e o leitor sendo bom leitor, a leitura vai gerar resultados satisfatórios. Textos mal escritos e leitores pouco hábeis vão gerar um resultado muito ruim.

Essas conclusões não são consideradas pacíficas, pois há autores (LANDOW, 1992; SNYDER, 1996; XAVIER, 2007; RAMAL, 2002) que defendem a leitura de hipertextos como sendo diferente da leitura de textos contínuos, uma vez que, para eles, textos e hipertextos seriam essencialmente diferentes. Nesses estudos, o hipertexto é visto como um texto não-linear que não tem eixo organizacional, nem centro. Além disso, esses autores argumentam que hipertextos requerem um leitor mais ativo, que deve ser um construtor de significado autônomo e independente. O leitor será também um co-autor, uma vez que pode adicionar informações ao texto.

Afinal, o que há de novo no hipertexto? Acredito que seja bom ponderar e não colocar o pêndulo nem de um lado nem de outro, mas equilibradamente no centro.

A noção de hipertexto foi criada por Vannevar Bush, que imaginou um equipamento que pudesse funcionar associativamente a 
exemplo da mente humana. Isso nos lembra que a mente pode ser vista como um grande hipertexto que é muitas vezes espelhado na linguagem e, logo, nos textos que sempre produzimos mesmo muito antes do advento da escrita. Isso não significa que a informática não tenha modificado em nada o universo dos textos da escrita e da leitura.

Com o texto digital, usamos menos o lápis e a borracha. Escrever é um ato diferente, mesmo da datilografia, pois podemos cortar, colar, editar, inserir tabelas e imagens com muito mais facilidade que antes e, além disso, hoje podemos salvar, inserir sons e animações, além de usar links que podem nos levar diretamente a outros textos, a filmes, músicas ou imagens. Aparecem novos gêneros textuais - muitos deles advindos da cultura impressa ou manuscrita, como o e-mail, o blog - que têm seus correspondentes nas cartas, bilhetes e diários - e novas formas de comunicação como mensagens eletrônicas, chats, torpedos (no celular). Isso certamente provoca mudanças no comportamento e no pensamento do leitor e no produtor de textos. Essa mudança, no entanto, não deve ser vista como uma substituição das habilidades que o leitor precisa ter para lidar com o texto impresso, por outras que serão exclusividade do meio digital, mas uma ampliação daquelas.

Se antes o aluno precisava encontrar uma informação no texto que o professor escolheu para ele ler, agora ele precisa entrar na Internet e encontrar textos. Isso não seria novidade se os alunos estivessem acostumados a entrar em bibliotecas e a encontrar textos sobre os assuntos que gostariam de aprender. Sabemos, no entanto, que essa não é uma prática comum em nossas escolas por motivos variados.

Se antes os textos contavam quase que exclusivamente com a linguagem verbal, agora eles contam também com outras linguagens que podem e devem ser incorporadas a eles. Sendo assim, o aprendiz precisa saber lidar com a multimodalidade tanto como leitor quanto como autor. Isso não significa que ele não precise saber lidar com o verbal. Pelo contrário, para ser um bom leitor e produtor de textos multimodais isto é, textos que lidam com diversas linguagens -, o sujeito precisa dominar uma série de habilidades de leitura e produção de textos verbais. Mas agora a essas habilidades outras devem somar-se, ampliando a lista, devido à incorporação, em práticas cada vez mais cotidianas, do não verbal. Precisamos lembrar que a multimodalidade é, há muitos anos, parte de nossos textos, como no cinema, nas revisas, jornais, cartazes, 
convites, cartões, livros ilustrados, entre outros. Talvez a diferença seja a de ser mais fácil as pessoas também produzirem esses textos multimodais, que podem ser impressos ou disponibilizados na Internet (sites, Orkut, Youtube, blogs, entre outros).

\section{TEXTUALIDADE E TEXTUALIZAÇÃO NO HIPERTEXTO}

Vale a pena, então, falar em hipertexto como alguma coisa completamente diferente de texto? Os processos de leitura e escrita vão ser diferentes no hipertexto? Não continuamos falando de texto? A textualidade do hipertexto vai ser diferente da textualidade de um texto impresso?

Muita coisa muda com a informática, muita informação está disponível na Internet, novos gêneros textuais são criados, novas formas de ler e de escrever são desenvolvidas. Para serem leitores, independente do suporte do portador de texto, de o texto estar impresso ou projetado na tela, há habilidades de leitura que são essenciais para a compreensão do texto e que os leitores precisam desenvolver. Essas habilidades podem variar de acordo com os gêneros, mas não há habilidades de leitura que sejam específicas do ambiente impresso ou do ambiente digital. Há sim diferenças na navegação dos textos, em como e onde o leitor vai encontrar as informações que procura (biblioteca, índices x mecanismos de busca), mas, uma vez encontradas, a compreensão do texto não depende tanto de o texto ser impresso ou digital, mas das habilidades de leitura que o leitor já desenvolveu. (COSCARELLI; SANTOS, no prelo)

O hipertexto exige busca, navegação, que são habilidades que não costumamos desenvolver em nossos alunos. Não ensinamos os estudantes a navegar nos textos impressos, buscando informações no jornal, nas revistas, nas enciclopédias nem nas bibliotecas. Normalmente entregamos a eles o texto que precisam ler e não os fazemos procurar por esses textos. $\mathrm{Na}$ Internet, buscar é importante. Os alunos precisam saber navegar, encontrar e selecionar informações relevantes para os seus propósitos, além de ser capazes de localizar informações, fazer vários tipos de inferência, reconhecer efeitos de sentido, estabelecer relações lógico-discursivas, entre outras. 
Para nos ajudar nessa reflexão, podemos voltar um passo e perguntar: o que é um hipertexto? Hipertexto é um texto com links? O que são links? Hipertexto é texto em ambiente digital? Hipertexto é um texto em ambiente digital que tem links para outros textos? Quando navegamos na Internet podemos perceber os mais diferentes textos apresentados em ambiente de rede, mas nem sempre há, nos textos, link para outros (piadas, horóscopo, artigos, etc.). Esses textos são hipertextos? Estar no ambiente digital transforma esse texto em hipertexto? Afinal, do que estamos falando quando dizemos hipertexto? É preciso cautela para evitar o deslumbramento e a apologia aos meios digitais que podem nos levar a raciocínios ou a conclusões equivocados.

Uma definição possível de hipertexto é a de que hipertextos são textos não lineares que oferecem links ou elos de ligação para outros textos, que podem inclusive ser imagens, gráficos, vídeos, animações, sons.

No hipertexto, a informação é organizada como uma rede em que os nós sejam porções de textos (ex. lista de itens, parágrafos, páginas) e links são relações entre esses nós (ex. associações semânticas, expansões, definições, exemplos; virtualmente qualquer tipo de relação que possa ser imaginada entre duas passagens de texto). (ROUET; LEVONEN; DILLON; SPIRO, 1996, p. 3)

Como se pode notar, as definições de hipertexto aplicam-se também a textos que não estão em ambiente digital, pois a presença de títulos, subtítulos, índices, pé de página, as redes causais, as cadeias referenciais entre tantos elementos, que marcam a não linearidade dos elementos do texto, fazem parte de textos de modo geral, não sendo particularidade dos textos em ambientes digitais (COSCARELLI, 2006).

Além disso, podemos entender que os links possam ser de vários tipos como notas de pé-de-página, citações, referências a outros textos e vozes, além de ícones, palavras azuis grifadas, entre outras convenções para indicar links no texto digital. O que reforça minha tese de que todo texto é um hipertexto e toda leitura é um processo hipertextual (COSCARELLI, 2005a, 2005b, 2006).

Precisamos ensinar nossos alunos a ler hipertextos? Precisamos ensinar nossos alunos a escrever hipertextos? Acredito que precisamos 
ensinar nossos alunos a lidar com textos e mais textos, gêneros e mais gêneros em todos os ambientes, inclusive o digital. Se o leitor tem habilidades leitoras bem desenvolvidas, ou seja, se é um bom leitor, ele transfere essas habilidades para novos ambientes (RIBEIRO, 2003), sendo também bom leitor de novos gêneros em novos suportes ou ambientes assim que se familiariza com os mecanismos de navegação dele. Devemos, então, ensinar os alunos a navegar em textos de todas as naturezas: impressos, orais, digitais, verbais, não-verbais e multimodais.

É possível, no entanto, que o hipertexto digital demande do leitor algumas habilidades específicas entre outras que também são demandadas pelo impresso. Textos em formato hipertextual podem demandar uma leitura diferente, no que diz respeito, por exemplo, à monitoração da navegação (COIRO; DOBLER, 2007), à produção de inferências (preditivas ou relacionais), à monitoração da leitura e à integração de informações de diferentes linguagens. Devemos nos lembrar que isso pode depender de vários fatores que não apenas o formato do texto, como por exemplo, a complexidade sintática, lexical e estrutural do texto, a familiaridade do leitor com o assunto, o objetivo da leitura, entre vários outros fatores que podem interferir na leitura (COSCARELLI, 2002; LIBERATO; FULGÊNCIO, 2007). A leitura de hipertextos exige também, inegavelmente, um know how da navegação no ambiente digital que inclui a seleção de links, a compreensão da interface, (NOVAIS, 2008) e a busca de informação (GUALBERTO, 2008; RIBEIRO, 2008).

\section{INFORMÁTICA NOS LIVROS DIDÁTICOS DE LÍNGUA PORTUGUESA}

Procurando saber como os livros didáticos de língua portuguesa lidam com a informática, e em especial com o hipertexto, Else dos Santos e eu (no prelo) fizemos um levantamento dos elementos dos ambientes digitais que aparecem no livro didático (LD). Procuramos verificar se e como LDs de Língua Portuguesa contribuem para o letramento digital dos alunos. Analisamos LDs recomendados pelo Programa Nacional do Livro Didático 2008 com pontuação alta, ou seja, analisamos as 10 coleções melhor pontuadas no PNLD 2008. 
Pudemos perceber que o uso de "links" é comum em LDs e que algumas páginas possuem um layout semelhante ao de páginas da Internet, com uma coluna à esquerda com informações variadas como um menu, como nesse exemplo de Soares (1999):

Estou para começar a escrever o bilhete solicitado. Mas me ocorre um outro texto. O "telegrama ao futuro" que Aníbal Machado insere no romance João Ternura. É um teleC. Aníbal Machado - romancista e contista, 1894-1964. grama que alguém lê em meio ao Carnaval na Cinelândia. Temos que divulgá-lo:

Muitos LDs trazem sugestões de sites para professores e alunos encontrarem mais informações sobre os temas que estão estudando. Mas os LDs raramente sugerem aos professores formas de explorar os sites indicados.

Podemos encontrar, em menor quantidade, propostas de desenvolvimento de projetos utilizando programas de computador variados. Há livros que propõem projetos utilizando programas como Excel, Word, Animator, programas de animação, PowerPoint etc. Entretanto, não há indicação para o professor nem para o aluno de como usar esses programas. Os autores desses LDs parecem partir do pressuposto de que todo mundo sabe ou deveria saber usar tais programas.

Raros são os casos em que alunos e professores recebem, no livro didático, instruções que detalham os passos da criação de produtos usando algum desses programas, a exemplo do que acontece na criação de uma homepage proposta em Takazaki (2008, p. 68) e apresentada a seguir: 


\section{Criando uma homepage a partir do Word}

Para fazer uma página (homepage) não é necessário ser "expert" em informática ou um grande "micreiro". O Word também lhe permite criar uma página. Ela já vem quase pronta. Basta você acrescentar as suas । informações.

Vamos criar uma homepage? Siga os passos abaixo e entre no mundo da Internet.

1. Clique a opção Arquivo Novo.

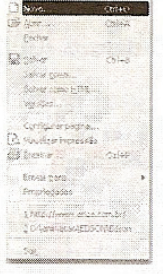

1

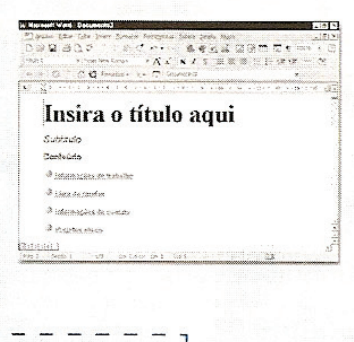

Experimente clicar diferentes tipos e estilos de página e verifique a de que você mais gostar. O Word exibirá as estações por detrás das caixas de diálogo. $\mathrm{O}$ Word criará a página conforme a seleção feita por você. Verifique que a Barra de Status indica que a homepage tem três páginas.

2. Aparecerá a tela ao lado. Clique a opção

Páginas da WEB,

em seguida, a opção

Assistente de Página

da WEB e, por fim, o botão $\mathbf{O K}$.
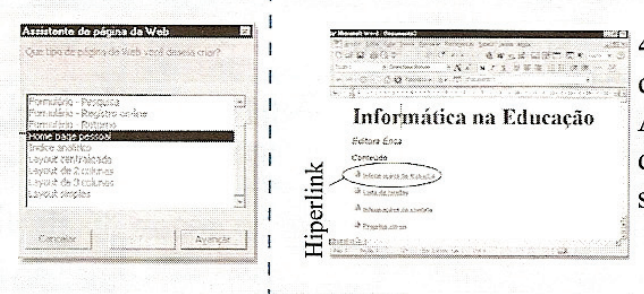

4. Selecione as linhas que contêm "INSIRA O TÍTULO AQUI" e "SUBTÍTULO", digite o título e o subtítulo da sua homepage.

3. Logo aparecerão as caixas de diálogo a seguir, perguntando que tipo de página você quer criar. No nosso exemplo iremos utilizar a Homepage Pessoal.
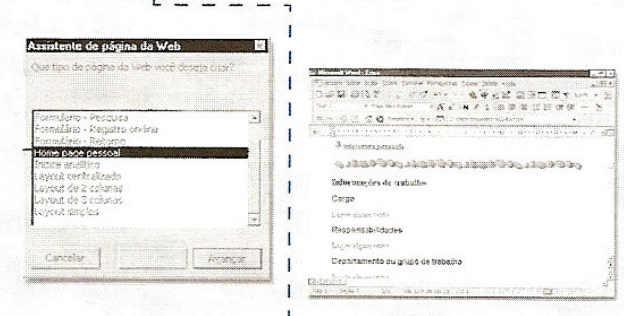

5. Para completar a sua homepage, clique cada hiperlink e acrescente o texto necessário. - Para navegar pela homepage utilize a Barra de Rolagem ou

- Clique a opção Homepage Pessoal e, em seguida, o botão Avançar.

- Clique a opção Outdoors e, em seguida, o botão

Concluir para escolher o estilo

da sua página. clique os "links". Perceba que, no final de cada "hiperlink", existe um link "voltar ao início", clique-o para voltar à tela principal.

6. Após concluir a sua homepage, não se esqueça de salvá-la. Clique a opção Arquivo - Salvar como. Automaticamente o Word salvará com o padrão HTML.

Depois que a sua homepage estiver pronta, fale com o seu provedor, para incluí-la na Internet, mas lembre-se: os provedores, geralmente, cobram uma taxa de serviço que varia de acordo com o tamanho da homepage e do tempo que ela ficará disponível.

TAJRA, S.F; ANTONIO, L. Q. Projetando no computador, São Paulo: Érica, 1997, p. 124. (Adaptada) 
Alguns LDs procuram apresentar aos alunos vocábulos, emoticons, e termos que se referem à navegação. Há livros que criam um glossário com alguns termos que circulam na rede. No entanto, nenhuma proposta de reflexão linguística, reconhecimento desses termos ou conceitos em ambientes digitais ou de uso desses termos é feita a partir da apresentação desses itens.

Em alguns materiais, a Internet aparece como tópico de algum texto que precisa ser lido pelos alunos, mas normalmente não há propostas práticas que orientem o aluno a entrar nela e procurar informações ou a produzir algum texto lá.

O e-mail e o blog são os textos do ambiente digital mais explorados nos LDs. Em alguns casos os alunos são levados a ler e a responder mensagens e a compreender a lógica dos endereços eletrônicos (ou endereços de sites) e a analisar a linguagem de algum texto de blog.

Raros são os casos em que há comparação entre o impresso e o digital como poderia acontecer com jornal nas duas versões ou entre o oral e o escrito como o telefonema e o chat. Seriam boas oportunidades de discutir com os alunos sobre diferentes tratamentos dados aos textos em função do suporte ou ambiente (impresso ou digital) e da modalidade (oral ou escrita).

A palavra hipertexto foi encontrada nas referências bibliográficas de dois textos retirados da seção Hipertexto da Revista Veja e nenhum trabalho foi feito com ela.

A análise que fizemos desses materiais nos mostra que o ambiente digital é reconhecido pelos LDs, mas não é satisfatoriamente explorado por eles. Isso me leva à pesquisa feita por Mônica Araújo (2007) que mostra que o papel da escola como agência de letramento digital é muito diferente do papel da casa. À escola cabe didatizar e limitar os percursos dos alunos no computador a determinados sites informativos (ensinar a usar) ${ }^{2}$. Em casa, por outro lado, as crianças podem conversar no MSN, participar de Orkut, explorar o Youtube, fazer e visitar blogs, jogar, etc. (usar, explorar o computador). Uma divisão parece estar se consolidando: a escola assumindo uma abordagem pedagógica do

\footnotetext{
${ }^{2}$ Sabemos que em muitas escolas os computadores são programados para bloquear o acesso a blogs, Youtube, Google Earth, Orkut, MSN, entre muitos outros sites e mecanismos da web.
} 
computador e a casa incorporando uma abordagem mais livre e lúdica dele. Podemos então nos perguntar se precisamos separar o lúdico do pedagógico. A fala de um dos alunos entrevistados por Mônica revela como ele identifica e aceita os papéis de cada lugar no que diz respeito ao computador: "na escola é um lugar de aprender... aprender coisas boas, não é chegar aqui em casa falando que jogou o joguinho do arroto e a mãe vai ficar doida brigando com a professora" (9anos).

Há um medo por parte dos pais e de alguns professores de as crianças desaprenderem quando navegam, medo de elas viciarem, de obterem informação não confiável, de elas se isolarem do mundo real, como se o computador fosse um agente do mal, um vilão. Esse medo é reforçado pela mídia que costuma apresentar o computador como um agente negativo na aprendizagem e na socialização dos usuários.

Nós sabemos que ninguém corre o risco de desaprender quando navega, seja em ambientes digitais ou em materiais impressos, mas é preciso ver o que se está aprendendo e algumas vezes interferir nesse processo a fim de otimizar ou orientar a aprendizagem, mostrando aos usuários outros temas, outros caminhos, outras possibilidades diferentes daquelas que eles encontraram sozinhos ou daquelas que eles costumam usar. É preciso, algumas vezes, negociar o uso para que ele não seja exclusivo, uma vez que há outros meios de comunicação, outros meios de informação e outras alternativas de lazer. É uma questão de equilibrar e não de culpar.

A mídia culpa os computadores por muitos males que eu acredito que eles devem estar é sanando. Será que as pessoas escrevem mal porque usam computadores? Sou capaz de apostar que quem usa computadores escreve e lê melhor que quem não usa. Essa culpa costuma ser aceita por muitas escolas e por alguns pais.

O que pudemos perceber na nossa análise dos LDs é que eles contribuem muito pouco para o letramento digital tanto do aluno quanto do professor, pois lidam com o computador, na grande maioria das vezes, como uma fonte de informação. Raramente o computador é tratado como meio de comunicação, de socialização ou de divulgação de informações, isto é, os alunos não são estimulados a estabelecer comunicação com outras pessoas via computador (amigo, estudantes de outras escolas, autores, pesquisadores, etc.), nem são estimulados a fazer 
parte da rede como colaboradores, criando sites, blogs, comentando textos, propondo ou enriquecendo verbetes em wikis, entre tantas outras atividades que podemos fazer usando o computador.

Considerações finais

O que proponho é repensarmos a idéia de hipertexto e dos ambientes digitais. Que eles não sejam vistos como uma ruptura (COSCARELLI, 2006) em relação ao impresso, mas como uma continuidade dele. Talvez não seja o caso de pensarmos como a textualidade do hipertexto digital seja diferente da textualidade do texto impresso, mas em como outras linguagens se incorporam a ele (o vídeo, a animação e o som, por exemplo). É possível que leituras e escritas estejam diferentes, não porque os textos sejam diferentes, mas porque as situações de produção sejam distintas, podendo duas ou mais pessoas fazer intervenções ao mesmo tempo nos textos a exemplo do que acontece nos Google docs. Talvez a leitura silenciosa sem comentários esteja cedendo espaço para leituras coletivas e comentadas (de volta ao passado) quando, por exemplo, os alunos compartilhavam a mesma máquina. A informática pode estar transformando algumas práticas em relação ao texto, possibilitando diferentes gestos e comportamentos de leitura que parecem evidenciar mais uma mudança na história da cultura escrita, ampliando assim nossas práticas letradas.

Um olhar sobre o LD nos mostra uma realidade preocupante que não nega a existência do universo digital, mas que também não investe nele. Por que isso acontece? E com essa, uma série de outras perguntas aparecem: como deveria ser o trabalho com o hipertexto digital? A navegação e a familiarização dos aprendizes com esse ambiente é importante, mas, no que diz respeito à leitura e à produção de texto, eles vão precisar adquirir um conjunto totalmente novo de habilidades? Vamos precisar construir uma noção de textualidade específica para os hipertextos? Parece que este não é o caminho. Precisamos compreender e ajudar nossos alunos a lidar com a convergência digital, com o texto que tem som, que tem imagem, que tem animação e mecanismos de navegação, que exige buscas e possibilita muitas escolhas, mas não podemos fazer isso sem que ele domine também o impresso e as várias habilidades fundamentais de leitura e produção de textos que vão servir de base para sua atuação como bom leitor e bom produtor de textos independentemente do ambiente em que essas atividades ocorrerem. 
É preciso conhecer ou dominar o impresso antes de ir para o digital? Talvez seja o caso de repensarmos a direção da aprendizagem. Pode ser que em pouco tempo os alunos estejam tão familiarizados com os ambientes digitais que seja melhor começar por eles para chegarmos ao impresso. Essa é uma possibilidade que não podemos deixar de considerar e para a qual precisamos nos preparar. Daí a importância de o professor se enfronhar neste mundo digital, conhecendo seus recursos, seus gêneros, suas linguagens e seu potencial, a fim de que possa usá-los ou explorá-los em suas atividades profissionais.

Precisamos ainda fazer mais reflexões e estudos sobre a noção de hipertexto, pensando sobre o que há realmente de novo nos ambientes digitais no que diz respeito à textualidade, e discutindo como esses ambientes podem nos ajudar a fazer com que nossos alunos sejam bons leitores e bons produtores de textos, inclusive aqueles dos ambientes digitais.

O hipertexto pode não exigir uma nova concepção de texto, de textualidade e de textualização, mas os ambientes digitais vão exigir novos professores. Ou será que as escolas e os LDs estão certos de deixar por conta dos pais e dos próprios alunos a tarefa de aprender a lidar com esse novo universo?

\section{REFERÊNCIAS}

ARAÚJO, M.D.V. Formas e condições de apropriação da cultura escrita digital por crianças de camadas médias. Dissertação (Mestrado em Educação) - Universidade Federal de Minas Gerais, 2007.

COIRO, J.; DOBLER, E. Exploring the online reading comprehension strategies used by sixth-grade skilled readers to search for and locate information on the Internet. Reading research quarterly, v. 42, n. 2, p. $214-$ 257, 2007.

COSCARELLI, C. V. Leitura em ambiente multimídia e a produção de inferências. Tese (Doutorado em Estudos Linguísticos) - Faculdade de Letras, Universidade Federal de Minas Gerais, 1999.

. Entendendo a leitura. Revista de estudos da linguagem, Belo

Horizonte: UFMG, v. 10, n. 1, p. 7-27, jan./jun. 2002. 
. Leitura de hipertexto. 2005a. Relatório de pesquisa - Capes Processo BEX 0418/04-8. (mimeo)

. Leitura de hipertextos. In: ENCONTRO NACIONAL SOBRE HIPERTEXTO, 1, Recife, UFPE, outubro de 2005b. Anais... (CD Rom)

Os dons do hipertexto. Littera: revista de Linguística e Literatura, Pedro Leopoldo, Faculdades Integradas Pedro Leopoldo, v. 4, n. 4, p. 7-19, jul./dez. 2006.

A leitura de hipertextos: charges. In: ARAÚJO, J. C.; DIEB, M.

(Orgs.). Linguagem \& Educação: fios que se entrecruzam na escola. Belo Horizonte: Autêntica, 2007. p. 65-88.

; SANTOS, E. M. O livro didático como agente de letramento digital.

Belo Horizonte: CEALE, 2007. (no prelo)

COSTA VAL, M. G. Texto, textualidade e textualização. In: CECCANTINI, J. L. T.; PEREIRA, R. F.; ZANCHETTA JR., J. Pedagogia cidadã: cadernos de formação - Língua Portuguesa. V. 1. São Paulo: UNESP-Pró-Reitoria de Graduação, 2004. p. 113-128.

DIAS, M. C. A influência do modo de organização de hipertextos na compreensão. Dissertação (Mestrado em Estudos Linguísticos) - Faculdade de Letras, Universidade Federal de Minas Gerais, 2008.

GUALBERTO, I. M. T. A influência dos hiperlinks na leitura de hipertexto enciclopédico digital. Tese (Doutorado em Estudos Linguísticos) - Faculdade de Letras, Universidade Federal de Minas Gerais, 2008.

LANDOW, G. P. Hypertext 2.0. Baltimore: Parallax, 1992.

LIBERATO, Y.; FULGÊNCIO, L. É possível facilitar a leitura: um guia para escrever claro. São Paulo: Contexto, 2007.

NOVAIS, A. E. Leitura nas interfaces gráficas de computador: compreendendo a gramática da interface. Dissertação (Mestrado em Estudos Linguísticos) - Faculdade de Letras, Universidade Federal de Minas Gerais, 2008.

RAMAL, A. C. Educação na cibercultura. Porto Alegre: Artes Médicas, 2002.

RIBEIRO, A. E. Ler na tela. Dissertação (Mestrado em Estudos Linguísticos) - Faculdade de Letras, Universidade Federal de Minas Gerais, 2003. 
Navegar lendo, ler navegando: aspectos do letramento digital e da leitura de jornais. Tese (Doutorado em Estudos Linguísticos) - Faculdade de Letras, Universidade Federal de Minas Gerais, 2008..

ROUET, J.-F.; LEVONEN, J.; DILLON, A,; SPIRO, R. Hypertex and cognition. New York: Lawrence Erlbaum Associates, 1996.

SNYDER, I. Hypertext: the electronic labyrinth. New York: NY University Press, 1996.

SOARES, M. Uma proposta para o letramento. São Paulo, Moderna, 1999.

TAKAZAKI, Heloísa Harue. Língua Portuguesa - linguagens no século XXI. São Paulo: Ibep Ltda., 2008.

XAVIER, A. C. A dança das linguagens na web: critérios para a definição de hipertexto. In: SILVA, T. C.; MELLO, H. (Orgs.). Conferências do V

Congresso Internacional da ABRALIN. Belo Horizonte: FALE/UFMG, 2007. p. 199-210.

Recebido em 25/01/09. Aprovado em 18/07/09.

Title: Texts and hypertexts: looking for balance

Author: Carla Viana Coscarelli

Abstract: This paper discusses the question of "to what extent do we need to treat hypertexts differently from texts, as far as textuality features are concerned?". I argue in favor of the idea that every text is a hypertext and that every reading activity is a hypertextual process. I believe that if the text is well written, that is to say, if it is adequate to the reader, and if the reader is proficient, the reading process will generate satisfactory results. Badly written texts and non-proficient readers will generate bad results, no matter the format of the text (print or hypertext). Therefore, we need to teach our students to deal with different texts, from different genres, in distinct environments, including the digital one. This article presents elements of the digital environment that can be found in Portuguese textbooks, in order to verify the contribution of these materials to the students' digital literacy.

Keywords: hypertext; textuality; textbooks.

Titre: Textes et hypertextes: cherchant l'équilibre

Auteur: Carla Viana Coscarelli

Résumé: Dans ce texte, je discute la question “jusqu'à quel point nous avons besoin de traiter l'hypertexte de forme différente de celle du texte en ce qui concerne les facteurs de la textualité". Je fais la défense qui admet que tout texte est um hypertexte et que toute lecture est un procédé hypertextuelle. Je crois que si le texte est bien écrit, 
c'est-à-dire, convenable au lecteur, et si le lecteur est bon, la lecture va produire des résultats satisfaisants. Des textes mal écrits et des lecteurs peu habiles vont produire un résultat mauvais indépendant du format de la présentation du texte (imprimé ou hypertextuel). On a besoin, cependant, d'enseigner nos élèves à s'en tirer avec des textes variés, de genres diversifiés, dans toutes les milieux, y compris celui du digital. Je présente une étude des éléments des milieux digitaux qui sont présents dans des livres didactiques de Langue Portugaise, ayant comme objectif celui de vérifier comment ces matériels contribuent dans l'alphabétisation digitale des élèves.

Mots-clés: hypertexte; textualité; livre didactique.

Título: Textos e hipertextos: buscando el equilibrio

Autor: Carla Viana Coscarelli

Resumen: En este texto discuto la cuestión "hasta que punto precisamos tratar el hipertexto de forma diferente del texto en lo que dice respecto a los factores de textualidad". Defiendo que todo texto es un hipertexto y que toda lectura es un proceso hipertextual. Creo que si el texto está bien escrito, o sea, está adecuado al lector, y el lector es bueno, la lectura va a generar resultados satisfactorios. Textos mal escritos y lectores poco hábiles van a generar un resultado muy malo independiente del formato de presentación del texto (impreso o hipertextual). Precisamos, por lo tanto, enseñar a nuestros alumnos a lidiar con textos variados, de géneros diversificados, en todos los ambientes, inclusive el digital. Presento un levantamiento de los elementos de los ambientes digitales que aparecen en libros didácticos de Lengua Portuguesa, a fin de verificar como esos materiales contribuyen para el letramiento digital de los alumnos.

Palabras-clave: hipertexto; textualidad; libro didáctico. 